\title{
Coulisses
}

Revue de théâtre

10 | Printemps 1994

Varia

\section{Le Centre de Rencontres : changement de direction}

\section{J.J. Mutin}

\section{OpenEdition}

Journals

Édition électronique

URL : http://journals.openedition.org/coulisses/2819

DOI : $10.4000 /$ coulisses. 2819

ISSN : 2546-9460

\section{Éditeur}

Presses universitaires de Franche-Comté

\section{Édition imprimée}

Date de publication : 1 juin 1994

Pagination : 17-18

ISSN : 1150-594X

\section{Référence électronique}

J.J. Mutin, «Le Centre de Rencontres : changement de direction », Coulisses [En ligne], 10 | Printemps 1994, mis en ligne le 15 mars 2019, consulté le 31 octobre 2019. URL : http://journals.openedition.org/ coulisses/2819; DOI : 10.4000/coulisses.2819

Ce document a été généré automatiquement le 31 octobre 2019

Coulisses 


\section{Le Centre de Rencontres : changement de direction ${ }^{1}$}

\section{J.J. Mutin}

Créé en 1978 par Jacques VINGLER ${ }^{2}$, alors Conseiller Technique et Pédagogique à Jeunesse et Sports et Jacques FORNIER ${ }^{3}$, Comédien et metteur en scène, le Centre de Rencontres, 27, rue de la République à Besançon est né d'une croyance très forte dans les pouvoirs créatifs de chacun d'entre nous. C'est à l'origine un lieu de découverte, d'apprentissage, d'expérimentation, de réalisation conduisant à la révélation et au développement des potentialités de l'expression individuelle et collective et à leur maîtrise.

\section{Le Centre de Rencontres}

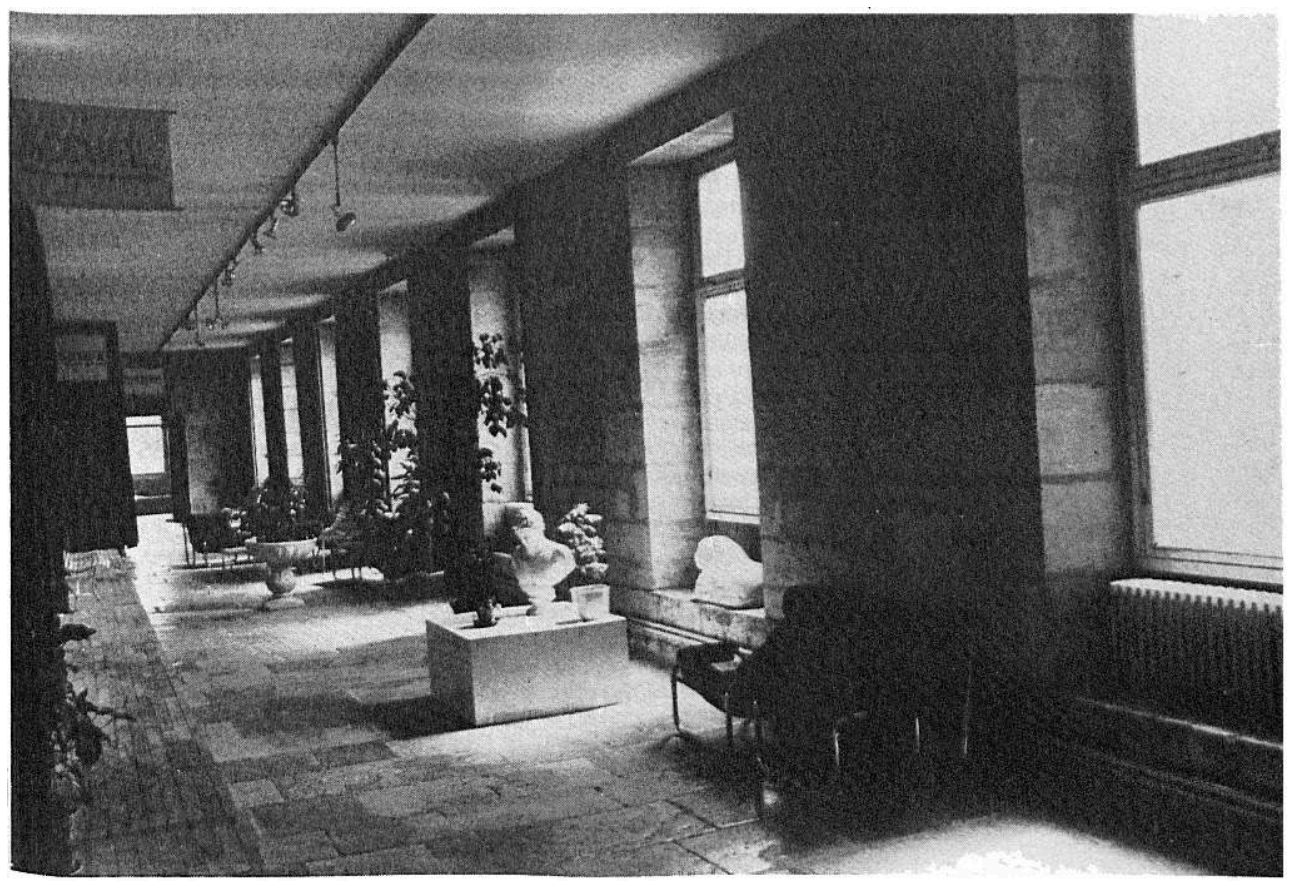


La pratique de l'art théâtral, dominante de ses activités, est ouverte à un large public et développée dans plusieurs directions: l'initiation, la formation professionnelle (initiale et continue), la recherche, avec une application directe dans les différents milieux concernés : le théâtre amateur, le théâtre professionnel, le théâtre en milieu scolaire.

L'arrivée du nouveau directeur Jean-Jacques MUTIN, homme de théâtre et universitaire, même si elle ne change pas radicalement ces grandes orientations, va infléchir l'action à mener vers certaines priorités :

1. Faire en sorte que ce lieu assure pleinement sa fonction de "Centre Régional de Formation aux Arts et Techniques du Spectacle.», en multipliant les occasions de collaboration avec tout le tissu associatif de proximité.

2. Renouer organiquement, pour tous les types de formation proposés, avec la programmation théâtrale locale, en établissant des passerelles avec les partenaires, sur les bases du professionnalisme, de la rigueur et de la qualité.

3. Créer un secteur d'écriture théâtrale contemporaine par le biais de résidences d'auteurs, qui écriront « en phase » avec la réalité socio-historico-géo-politique du lieu.

4. Développer les pratiques du théâtre autour de trois axes :

- la formation des publics

- ateliers de pratiques artistiques (jeu, lecture du texte et de la représentation) pour adultes et adolescents.

- les enseignements artistiques, en milieu scolaire et universitaire.

- la formation des enseignants, des bibliothécaires...

- la formation des artistes locaux / formation professionnelle :

- initiale (en lien avec l'université de Franche-Comté)

- continue (en lien avec l'A.N.P.E. Spectacles, l'AFDAS...)

- la recherche en matière théâtrale : débats, rencontres, colloques, publications.

5. Organiser régulièrement des « temps forts »:

- rencontres de théâtre amateur, théâtre lycéen.

- rencontres, au niveau européen, des centres de formation théâtrale à vocation professionnelle.

A SUIVRE...

\section{NOTES}

1. Les notes sont de la rédaction.

2. Jacques VINGLER a écrit différents articles pour Coulisses.

Une enquête approfondie sur les :

- « Théâtres d'amateurs en Franche-Comté ", Coulisses n 2

- « Théâtres d'amateurs en Franche-Comté, (suite) », Coulisses n ${ }^{\circ} 5$

Une réflexion pratique : «Lire/dire Molière, déchiffrage de la partition », Coulisses n 9, p. 67.

3. Jacques FORNIER a été interviewé par Philippe BARON, Coulisses nº 7, p. 18. 


\section{AUTEUR}

J.J. MUTIN

Directeur du Cendre de Rencontres 